\title{
MADURACIÓN DE CHORIZO Y SALCHICHÓN DE CHATO MURCIANO CON DIFERENTES CULTIVOS INICIADORES (BACTERIAS ÁCIDO- LÁCTICAS Y ESTAFILOCOCOS)
}

Ripening of chorizo and salchichón from Chato Murciano pig using different starter cultures (lactic acid bacteria plus staphylococci).

\author{
Sancho Bañón*, Alexandra Martínez y Alejandro Manuel López \\ Departamento de Tecnología de los Alimentos, Nutrición y Bromatología. Facultad de Veterinaria. \\ Universidad de Murcia. Campus Espinardo, 30071. Murcia, España.
}

*Autor para correspondencia: y dirección actual: Sancho Bañón Arias. Tel: 00 34-868-888265, Fax: 00 34-868-884147, Email: sanchoba@um.es.

\section{RESUMEN}

El presente estudio evalúa las características tecnológicas de dos cultivos iniciadores comerciales utilizados para madurar chorizo y salchichón cular de cerdo Chato Murciano. Ambos embutidos fueron elaborados alternativamente con un cultivo acidificante rápido enriquecido con estafilococos (3 Pediococcus pentosaceus, 7,5 Staphylococcus xylosus y 1,5 Staphylococcus carnosus) y con un cultivo tradicional para embutidos crudocurados (3 Lactobacillus sakei, 1,5 S. xylosus y 1,5 S. carnosus) (dosis expresada como $10^{7} \mathrm{ufc} \mathrm{g}^{-1}$ masa). Se determinaron parámetros de maduración (composición, $\mathrm{a}_{\mathrm{w}}, \mathrm{pH}$, color CIELAB, aerobios mesófilos totales, bacterias ácido-lácticas, micrococáceas, mohos y levaduras, acidez de la grasa e índice de proteólisis) y sensoriales (color, olor, sabor y textura) en producto final. Ambos cultivos iniciadores proporcionaron al chorizo y el salchichón similares características de maduración (acidificación, proteolisis y lipolisis), pese a su diferente formulación y picado. A excepción del $\mathrm{pH}$, las diferencias entre cultivos en los parámetros de maduración fueron en general poco relevantes. P. pentosaceus presentó una velocidad acidificante superior $a$ L. sakei, disminuyendo con más eficacia el pH del embutido. Por su parte, la combinación de L. sakei, S. xylosus y S. carnosus permitió alcanzar mayores recuentos finales de bacterias fermentativas, consiguiendo además moderar la caída del $\mathrm{pH}$, mejorar ligeramente el bouquet, en particular del chorizo, y sobre todo, reducir la acidez de ambos embutidos. El tipo de cultivo iniciador no influyó en el color del magro de ambos embutidos, mientras que los cambios de textura estuvieron relacionados con diferencias en el contenido en humedad y grasa. La sobredosificación con S.xylosus no aportó beneficios tecnológicos adicionales a los embutidos madurados con $P$. pentosaceus, ya que apenas se consiguió aumentar la carga inicial de micrococáceas con respecto al fermento tradicional. Por tanto, el uso de bacterias lácticas de gran potencial acidificante con altas dosis de estafilococos 
no mejora las propiedades de maduración del chorizo y salchichón cular de Chato Murciano elaborado con dosis alícuotas de cultivos de bacterias ácido-lácticas y estafilococos.

Palabras clave: embutido crudo-curado, fermentación, micrococos, lactobacilos, lactococos.

\section{ABSTRACT}

This study evaluated the different technological properties of two commercial starter cultures used to ripen two dry-cured fermented sausages (chorizo and salchichón) made with pork from the Murciano breed and stuffed in natural casing. The ripening of both sausages was started with a fast acidifying culture enriched with staphylococci (3 Pediococcus pentosaceus, 7.5 Staphylococcus xylosus and 1.5 Staphylococcus carnosus) or a standard culture (3 Lactobacillus sakei, $1.5 \mathrm{~S}$. xylosus and $1.5 \mathrm{~S}$. carnosus) (dosage expressed as $10^{7} \mathrm{cfu} \mathrm{g}^{-1}$ mass). The ripening properties (composition, $\mathrm{a}_{\mathrm{w}}, \mathrm{pH}, \mathrm{CIELAB}$ color, total viable counts, lactic acid bacteria, Micrococcaceae, moulds and yeasts, fat acidity and proteolysis index) and the sensory traits (color, odor , flavor and texture) were determined in fresh and/or dry-cured sausage. Both starter cultures provided similar ripening properties in chorizo and salchichón despite their different formulation and degree of mincing. With the exception of $\mathrm{pH}$, the differences in the ripening properties between the cultures were generally irrelevant. $P$. pentosaceus showed a higher acidifying rate than L. sakei, and more effectively decreased the $\mathrm{pH}$ of the sausages. The combination of L. sakei, S. xylosus and S. carnosus allowed higher final counts of fermentative bacteria to be reached, moderated the drop in $\mathrm{pH}$, slightly improved bouquet, especially in chorizo, and, especially, reduced the acidity of both sausages. In contrast, the type of starter culture did not influence the lean colour of either sausage, while the changes in texture were related with differences in moisture and fat content. Overdosage of S. xylosus did not provide additional technological benefits to the sausages started with P. pentosaceus, because it failed to increase the Micrococcaceae charge in fresh sausage compared with the levels attained using standard culture. It is concluded that the use of lactic bacteria of great acidifying potential, combined with high doses of staphylococci, does little to improve the ripening properties of Chato Murciano chorizo and salchichón started with an aliquot dose of lactic acid bacteria and staphylococci.

Key words: dry-cured sausage, micrococci, lactobacilli, lactococci.

\section{INTRODUCCIÓN}

Los embutidos crudo-curados fermentados de cerdo, como el salchichón y el chorizo han sido fabricados en la Europa Mediterránea desde la antigüedad a partir de razas porcinas autóctonas. Dichas razas han sido reemplazadas paulatinamente por otras razas más precoces y productivas, si bien ahora se abren nuevas oportunidades para criar este tipo de cerdos rústicos. La UE valora en gran medida la diversidad genética y ha puesto en marcha programas de recuperación de razas en peligro de extinción en Europa. El cerdo Chato Murciano fue oficialmente declarado como raza de especial protección en peligro de extinción en 1999, continuando dicha protección en la actualidad (R.D. 997/1999 y 2129/2008). Tras diversos trabajos de investigación sobre genética y producción porcina (Calvo et al., 2000; Peinado et al., 2003 y 2004, Poto et al., 2007; Galián et al., 2008 y 2009), finalmente se ha conseguido recuperar esta raza porcina y disponer de unas 500 cerdas reproductoras (Achamur, 2011).

Actualmente se está intentando desarrollar un mercado de productos cárnicos de calidad diferenciada y alto valor comercial, capaz de rentabilizar los altos costes de producción de la carne y de garantizar una producción de cerdos sostenible en los próximos años. Con este objetivo, la mayor parte de la cabaña actual de cerdo Chato Murciano se cría en régimen semiextensivo, donde los cerdos se alimentan con piensos especiales y se sacrifican a una edad y peso muy superior al de los cerdos comerciales (18 meses y $160 \mathrm{~kg}$ ) (Achamur, 2011). La producción de cerdos pesados de raza Chato Murciano ha permitido obtener una carne muy 
pigmentada, con una gran infiltración grasa y con un alto contenido en ácido oleico, características idóneas para elaborar productos crudocurados (Martínez et al., 2008; Martínez-Cachá et al., 2009; Salazar et al., 2009; Bañón et al., 2009 y 2010; Bedia et al., 2010).

Junto con la calidad de la carne, la microbiota tecnológica también juega un importante papel en la calidad de estos embutidos fermentados. Muchas bacterias fermentativas se encuentran de forma natural en la carne y en las tripas animales. Por ejemplo, Benito et al. (2007) aislaron un total de 192 bacterias lácticas autóctonas en salchichón y chorizo ibérico fermentado de forma natural, incluyendo varios tipos heterofermentativos. Una antigua práctica consistía en inocular masas cárnicas a lotes sucesivos de producto, sobre todo en producciones con cierto volumen y continuidad en el tiempo. Sin embargo, cada vez menos empresas cárnicas se arriesgan a elaborar embutidos crudo-curados sin cultivos iniciadores por razones de seguridad alimentaria. Actualmente, la mayor parte los embutidos fermentados de Chato Murciano, como la Longaniza, Sobrasada, Chorizo y Salchichón, se elaboran a escala industrial con tripa natural añadiendo cultivos iniciadores (Martínez et al., 2008; Bañón et al., 2009 y 2010; Bedia et al., 2010). El control de la fermentación va a ser crucial en estos embutidos, ya que la tripa natural contiene bacterias latentes conservadas en salmuera, bien adaptadas a la carne, que pueden aportar propiedades indeseables o incluso interferir en el desarrollo de los cultivos iniciadores (Leroy et al. 2006).

Los principales cultivos de maduración usados en los embutidos crudo-curados incluyen Micrococáceas (MIC) y Bacterias Ácido-Lácticas (BAL). Se suelen añadir dosis de 7-8 log ufc $\mathrm{g}^{-1}$ para alcanzar una concentración en la masa (6-7 log ufc $\mathrm{g}^{-1}$ ) suficiente para conseguir una fermentación eficaz de la carne (Carrascosa, 2001). Algunas especies muy utilizadas de MIC, como S. carnosus, S. xylosus y K. varians, poseen actividad nitrato reductasa, proteolítica y lipolítica, que contribuyen al enrojecimiento, el bouquet y la conservación de estos embutidos (Leroy et al., 2006). Las principales especies de BAL utilizadas son L. sakei, L. curvatus, L. plantarum, L. pentosus, L. casei, P. pentosaceus y $P$. acidilactici, las cuales pueden presentar diferente perfil tecnológico; por ejemplo, L. sakei es una BAL de origen cárnico bien adaptada a los embutidos y a las bajas temperaturas, mientras que $P$. pentosaceus es una bacteria de origen vegetal que proporciona acidificaciones rápidas y una elevada acidez final (Hugas y Monfort, 1997; Leroy et al., 2006; Ammor y Mayo, 2007). Las BAL predominan sobre la microbiota de estos embutidos y su función principal de las BAL es bajar el $\mathrm{pH}$ hasta valores de 4,6-5,1, un $\mathrm{pH}$ cercano al punto isoeléctrico de las proteínas miofibrilares, si bien algunas BAL presentan además actividad proteolítica y lipolítica, e incluso producen bacteriocinas. Los aspectos positivos de esta acidificación son varios: inhibición de microbiota patógena y alterante, aumento de la velocidad de secado, aumento de la firmeza al corte por mayor desnaturalización de las proteínas, activación de las proteasas endógenas, y mayor enrojecimiento por formación de óxido nítrico y nitrosomioglobina (Hugas y Monfort, 1997; Lücke, 2000; Ammor y Mayo, 2007).

La elección de diferentes especies y cepas de bacterias como cultivos iniciadores se basa en su capacidad para proporcionar homogéneamente propiedades beneficiosas a los embutidos. La sinergia entre diferentes bacterias es importante y su asociación debería mejorar a la suma de sus actividades metabólicas por separado. La actividad de BAL debe permitir un adecuado crecimiento de MIC, sobre todo al principio de la etapa de maduración (Hugas y Monfort, 1997; Leroy et al., 2006, Ammor y Mayo de 2007). Los cultivos iniciadores tradicionales suelen contener dosis alícuotas de BAL y MIC, si bien otras prácticas industriales (aplicadas actualmente a embutidos de Chato Murciano) combinan BAL acidificantes rápidas 
que garanticen la seguridad con altas dosis de MIC que potencien la calidad sensorial. Sin embargo, los cultivos iniciadores con fuerte potencial acidificante podrían no ser los más adecuados en embutidos de maduración lenta y prolongada, como el chorizo y salchichón cular de Chato Murciano, por lo que resulta necesario testar dichos cultivos.

El objetivo de este estudio fue determinar si el uso de cultivos de bacterias lácticas de gran potencial acidificante y altas dosis de estafilococos mejoraba o no las propiedades de maduración del chorizo y salchichón cular de Chato Murciano elaborado con dosis alícuotas de cultivos de bacterias ácido-lácticas y estafilococos.

\section{MATERIAL Y MÉTODOS}

\section{Diseño experimental}

Se evaluó el efecto de la adición de dos cultivos iniciadores sobre la maduración y calidad sensorial del chorizo y salchichón de Chato Murciano. Se determinaron diversos parámetros físico-químicos y microbiológicos en producto fresco (recién embutido) y final (tras 8 semanas de secado), y se procedió a la descripción sensorial de ambos embutidos crudo-curados. En total se analizaron por duplicado 12 piezas de cada tipo de embutido procedentes de dos lotes de fabricación diferentes. El modelo estadístico se diseñó completamente al azar considerando la adición de cultivos iniciadores como principal tratamiento. El efecto del tratamiento se determinó mediante ANOVA simple (Test de medias de Scheffe). Los cálculos estadísticos se realizaron con el programa Statistix 8.0 para Windows (Analytical Software, USA).

\section{Elaboración de embutidos}

La figura 1 recoge el diagrama de flujos del proceso de fabricación del salchichón y el chorizo cular de Chato Murciano. Los embutidos fueron elaborados por una industria local
(Elaborados Cárnicos de Lorca, Lorca, Murcia, España). La tabla 1 recoge la formulación de ambos embutidos. La materia prima estuvo compuesta por paleta deshuesada, diversos recortes de carne y tocino. El método de picado y amasado fue diferente para el chorizo y el salchichón. En el caso del chorizo, las piezas magras se picaron con una placa de $35 \mathrm{~mm}$ y cuchilla de 2 cortes, mientras que las piezas grasas se picaron por separado con una placa de $12 \mathrm{~mm}$ y un cuchilla de 4 cortes, empleando para ello una picadora de discos perforados (Laska GMBH, WW1302, Nu-Meat Technology, Girona, España). En el caso del salchichón, la materia prima se desmenuzó de forma conjunta utilizando discos perforados con placa de 3 ojos, 14 mm y $6 \mathrm{~mm}$, y con 2 cuchillas de 4-8 cortes. La masa de carne picada fue mezclada con los aditivos y especias en una amasadora a vacío (AMU102 Maquinaria Vall, Miralcamp, Lleida, España) durante 10 (chorizo) ó 3 minutos (salchichón).

El preparado comercial de aditivos y especias fue proporcionado por la empresa Juan Martínez Pérez, Santa Catalina de Monte (El Palmar, Murcia, España). Para regular la maduración del embutido, se añadieron dos cultivos iniciadores liofilizados comerciales cuyas principales características recoge la tabla 2. Los cultivos iniciadores fueron proporcionados por Cargill Texturizing Solutions Cultures (La Frete Sous Jouarre, France) y Christian Hansen (Barcelona, España). Siguiendo las especificaciones de revivificación recomendadas por ambos fabricantes, los cultivos iniciadores fueron descongelados y disueltos en agua libre de cloro y añadidos a la masa en una dosis total de 6 $10^{7} \mathrm{ufc} \mathrm{g}^{-1}$. Finalmente se dejó reposar la masa cárnica en una cámara a $2-4^{\circ} \mathrm{C}$ durante 24 horas para facilitar la interacción entre ingredientes y aditivos. Tras la maceración, la masa cárnica fue embutida en tripa cular porcina con un calibre de 50-52 $\mathrm{mm}$ en un equipo semi-automático a vacío (WF-612 Handtmann, Biberach/ Riss, Alemania). Las tripas fueron previamente 


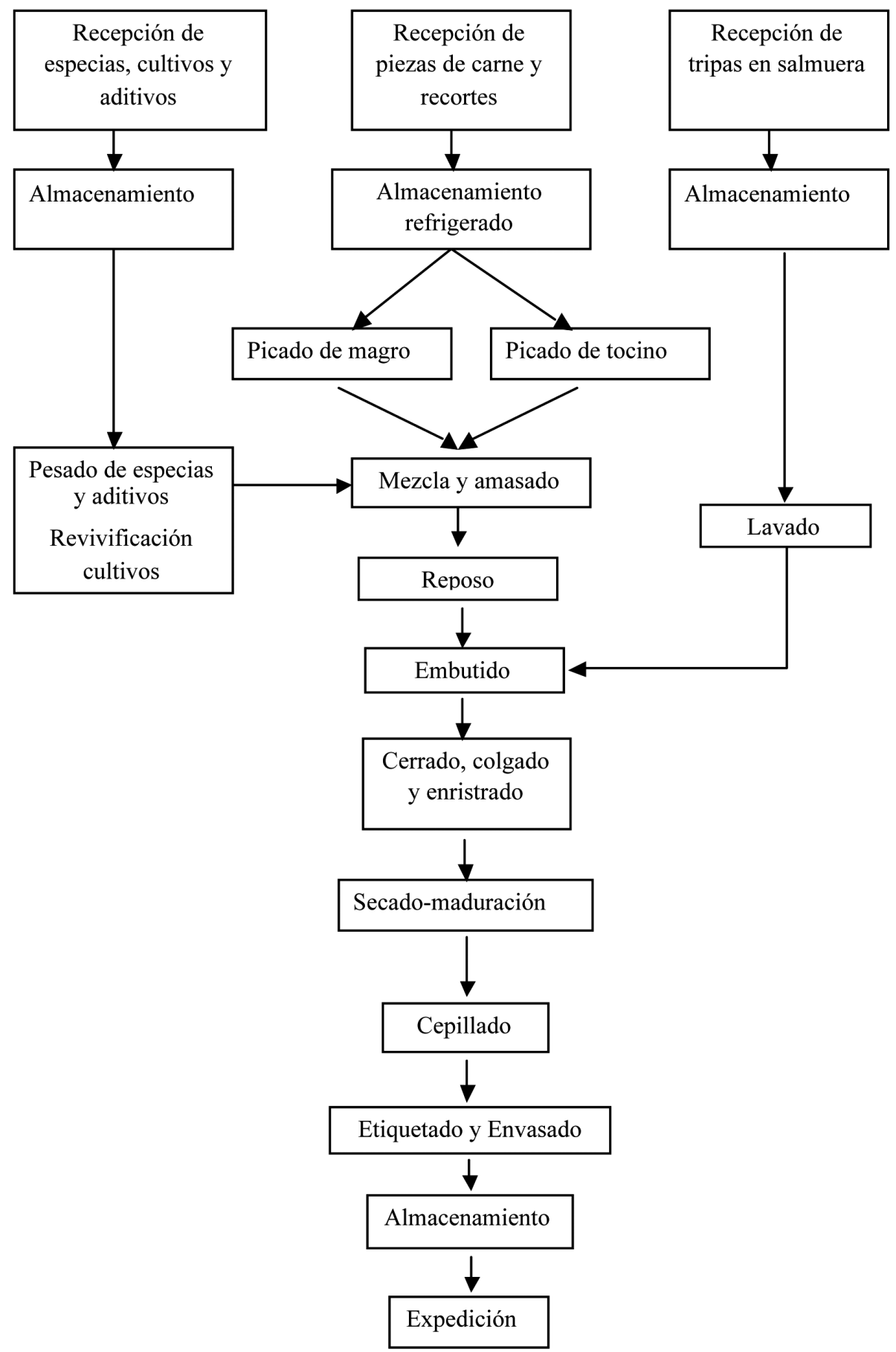

Figura 1. Diagrama de flujos de la elaboración de salchichón y chorizo cular 
Tabla 1. Formulación del chorizo y salchichón cular de Chato Murciano (CM)

\begin{tabular}{|l|c|c|}
\hline & Chorizo & Salchichón \\
\hline & $\mathbf{g ~ k g}^{-1}$ & \\
\hline Paleta deshuesada y recortes magros CM & & 677 \\
\hline Panceta y recortes grasos CM & 282 & 230 \\
\hline Agua declorada & 40 & 40 \\
\hline Cloruro de sodio & 23 & 23 \\
\hline Pimentón dulce & 6,7 & \\
\hline Pimentón dulce ahumado & 13,3 & 1 \\
\hline Pimenta blanca & & 1 \\
\hline Pimenta negra & 2 & 10 \\
\hline Ajo liofilizado & 1 & 3 \\
\hline Orégano & 3 & 0,15 \\
\hline Dextrosa & 10 & 0,15 \\
\hline Dextrina & 0,15 & 0,5 \\
\hline Nitrato potásico (E-252) & 0,15 & 10 \\
\hline Nitrito sódico (E-250) & 0,5 & \\
\hline Ascorbato sódico (E-301) & 10 & \\
\hline Proteína de leche & & \\
\hline
\end{tabular}

desaladas y lavadas minuciosamente. Las piezas recién embutidas se colgaron en carros de acero inoxidable con unas dimensiones de 1,20 $\mathrm{m}$ de ancho, 1,20 $\mathrm{m}$ de fondo y 2,20 $\mathrm{m}$ de alto y sometidas a secado durante 8 semanas en cámaras de ambiente controlado a una temperatura constante de $12 \pm 2^{\circ} \mathrm{C}$ y humedades relativas decrecientes del $90 \%$ al $75 \%$. Una vez concluido el secado, el exceso de microbiota externa fue eliminado mediante cepillado y las piezas de embutido fueron mantenidas a $2-4^{\circ} \mathrm{C}$ y $80-85 \%$ HR durante unas horas hasta su análisis.

\section{Análisis físico-químico}

La humedad expresada en porcentaje (\%) fue determinada de acuerdo con la Norma ISO
1442 (1997) utilizando una estufa de desecación (Heraeus, Madrid, España). La grasa total (expresada en \%) fue determinada según la Norma ISO 1443 (1973) utilizando una unidad de extracción HT2 1045 Soxtec System (Tecator Foss Analytical, Hilleroed, Dinamarca). Las cenizas $(\%)$ se analizaron por gravimetría previa incineración de la muestra en una mufla (Heraeus) (ISO 936: 1998). La actividad de agua $\left(\mathrm{a}_{\mathrm{w}}\right)$ se midió con un higrómetro Labmaster (Novasina TH200 Axair AG, Pfäffikon, Suiza) (ISO 21807, 2004). El pH se midió con un pHmetro micropH 2001 (Crison, Barcelona, España) equipado con un electrodo combinado Cat. 52-02 (Ingold Electrodes, Wilmington, EEUU) (ISO 2917, 1999). La acidez de la grasa (mg KOH /g grasa) fue determinada a partir de 
Tabla 2. Características tecnológicas de los cultivos iniciadores rápido $(\mathbf{R})$ y tradicional $(\mathbf{T})$

\begin{tabular}{|c|c|c|}
\hline Cultivo iniciador & $\mathbf{R}$ & $\mathbf{T}$ \\
\hline Nombre comercial & $\mathrm{CXP}+\mathrm{X} 100$ & TRADI300 \\
\hline Empresa & Cargill & Christian Hansen \\
\hline \multicolumn{3}{|l|}{ Dosis (ufc g-1) } \\
\hline P.pentosaceus & $3,0 \times 10^{7}$ & \\
\hline L. sakei & & $3,0 \times 10^{7}$ \\
\hline S. xylosus & $7,5 \times 10^{7}$ & $1,5 \times 10^{7}$ \\
\hline S. carnosus & $1,5 \times 10^{7}$ & $1,5 \times 10^{7}$ \\
\hline Velocidad acidificante & Rápida & Media \\
\hline Enrojecimiento & Intenso & Moderado \\
\hline Saborizante & Intenso & Moderado \\
\hline Fermentación lactosa & Negativa & Negativa \\
\hline \multicolumn{3}{|l|}{ Tolerancias } \\
\hline LAB & $15-35^{\circ} \mathrm{C} />3,8 \mathrm{pH} /<70 \mathrm{~g} \mathrm{NaCl} \mathrm{l}^{-1}$ & $15-35^{\circ} \mathrm{C} />3,5 \mathrm{pH} /<90 \mathrm{~g} \mathrm{NaCl} \mathrm{l}^{-1}$ \\
\hline Estafilococos & $10-35^{\circ} \mathrm{C} />4,5 \mathrm{pH} /<120 \mathrm{~g} \mathrm{NaCl} \mathrm{l}^{-1}$ & $10-35^{\circ} \mathrm{C} />4,5 \mathrm{pH}<120 \mathrm{~g} / \mathrm{NaCl} \mathrm{l}^{-1}$ \\
\hline
\end{tabular}

grasa extraída con una mezcla de cloroformo y metanol, mediante valoración con hidróxido potásico. El color objetivo se midió por reflectancia con un colorímetro CR400 R-200/08 Chroma Meter II (Minolta, Milton Keynes, Reino Unido). Para ello se empleó un iluminante D65, observador estándar $2^{\circ}$ (CIE 1931; x $2 \lambda$, $\mathrm{y} \lambda, \mathrm{z} \lambda)$ y un tubo de proyección de luz CRA3f con un diámetro de apertura de $10 \mathrm{~mm}$. Los resultados se expresaron como unidades CIELAB (adimensionales): Luminosidad (L*) (de 0 a 100); rojo-verde (a*) (valores negativos indican verde y valores positivos indican rojo); y amarillo-azul $\left(b^{*}\right)$ (valores negativos indican azul y valores positivos indican amarillo). El aparato fue calibrado con una placa de cerámica blanca (CR-A43).

El nitrógeno no proteico (NNP) y total (NT) se determinaron por el método Kjeldahl utilizando una unidad de digestión-destilación 423/326 (Büchi Labortechnik AG Flawil, Suiza) y un valorador 702 SM Titrino (Methrom, Schweiz,
Zofingen, Suiza) equipado con un electrodo combinado de pH 6.0233.100 (Methrom) (Norma ISO 937: 1981). El nitrógeno no proteico fue determinado previa precipitación de las proteínas con ácido tricloroacético. El índice de proteólisis (\%) se calculó a partir de la relación NT/NNP.

\section{Análisis microbiológico}

Se realizaron recuentos (log ufc $\mathrm{g}^{-1}$ ) de aerobios mesófilos totales (ISO 4833, 2003), bacterias ácido-lácticas (ISO 15214: 1998), micrococáceas, mohos y levaduras (ISO 215272, 2008). Las muestras fueron manipuladas asépticamente en una campana de flujo laminar (Bio-II-A Telstar, Terrasa, Barcelona, España) y homogeneizadas en bolsas estériles con agua de peptona (Oxoid Ltd. CM0087. Basingstoke, Hampshire, Reino Unido) empleando un mezclador tipo Masticator (IUL Instruments, GMBH, Königswinter, Alemania). Los medios de cultivo y las condiciones de incubación em- 
Tabla 3. Productos cárnicos de referencia empleados para la cuantificación de atributos sensoriales

\begin{tabular}{|l|c|c|c|c|}
\hline \multicolumn{1}{|c|}{ Escala } & \multicolumn{2}{|c|}{ Chorizo } & \multicolumn{2}{c|}{ Salchichón } \\
\hline Apariencia & & & & $\mathbf{5}$ \\
\hline Color magro & C. Alejandro Barbacoa & C. Guijuelo J. Martín & S. pimienta & S. Valle Santina \\
\hline Color grasa & C. Alejandro Barbacoa & C. Guijuelo J. Martín & S. pimienta & S. Valle Santina \\
\hline Olor & & & & \\
\hline Carne crudo-curada & C. Je-Ve & C. Ibérico Mafresa & S. Alcampo & S. Valle Santina \\
\hline Pimentón/Pimienta & C. Ibérico Mafresa & Sobrasada Crisol & S. Alcampo & S. pimienta \\
\hline Ácido & C. Ibérico Mafresa & C. Je-Ve & S. Casa Riera & S. Alcampo \\
\hline Rancio & C. Ibérico Mafresa & Tocino rancio & No detectable & Tocino rancio \\
\hline Sabor & & & & \\
\hline Carne crudo-curada & C. Je-Ve & C. Ibérico Mafresa & S. Vela & S. Valle Santina \\
\hline Pimentón/Pimienta & C. Ibérico Mafresa & C. Je-Ve & S. Monteporrino & S. pimienta \\
\hline Ácido & C. Ibérico Mafresa & C. Je-Ve & S. Monteporrino & S. pimienta \\
\hline Rancio & C. Ibérico Mafresa & Tocino rancio & No detectable & Tocino rancio \\
\hline Textura & & & & \\
\hline Dureza & C. Je-Ve & Morcón & S. pimienta & S. Casa Riera \\
\hline Jugosidad & C. Pavo & C. Je-Ve & S. Alcampo & C. Je-Ve \\
\hline Untuosidad & & & S. Alcampo & S. Valle Santina \\
\hline
\end{tabular}

pleados fueron PCA (Oxoid CM0325) y 48h / $37^{\circ} \mathrm{C}$ para aerobios mesófilos totales, Agar MRS (Oxoid CM0361) y $72 \mathrm{~h} / 30^{\circ} \mathrm{C}$ para BAL, Agar Manitol Sal (Oxoid CM0085) y $72 \mathrm{~h} / 37^{\circ} \mathrm{C}$ para MIC y Rosa de Bengala con Cloranfenicol (Oxoid CM0549) y $120 \mathrm{~h} / 25^{\circ} \mathrm{C}$ para mohos y levaduras. La incubación se realizó una estufa de cultivo modelo 207 (Selecta, Abrera, Barcelona, España).

\section{Análisis sensorial}

Se realizó un análisis sensorial descriptivo cuantitativo (Norma ISO 4121, 2003) utilizando 8 panelistas seleccionados y entrenados de acuerdo con la Norma ISO 8586-1 (1993). Los panelistas tenían experiencia previa en el análisis descriptivo cuantitativo de productos cárnicos crudo-curados. Durante las cuatro sesiones de entrenamiento se identificaron y cuantificaron diversos atributos sensoriales, tanto del chorizo, como del salchichón. La tabla 3 muestra los descriptores sensoriales seleccionados y los productos cárnicos de referencia para el chorizo y el salchichón cular de Chato Murciano. La escala utilizada fue de 1 (mínimo) a 5 (máximo). Cada panelista evaluó un total de 6 muestras por lote de fabricación en una sala de catas normalizada. 


\section{RESULTADOS}

\section{Chorizo cular de Chato Murciano}

La tabla 4 muestra la composición proximal y los parámetros de secado-maduración del Chorizo de Chato Murciano. No se observaron diferencias significativas entre ambos tratamientos en la composición proximal del chorizo fresco. Tras el curado, tampoco se encontraron diferencias de humedad entre ambos tratamientos, si bien el chorizo R (elaborado con cultivo iniciador "rápido") presentó un mayor porcentaje de proteína total y un menor porcen- taje de grasa total que el chorizo T (elaborado con cultivo iniciador "tradicional"). Pese a que ambos chorizos se elaboraron con los mismos ingredientes, las materias primas cárnicas son a menudo heterogéneas, lo que puede generar diferencias de composición entre diversos lotes de embutido sobre todo cuando su picado es grosero, como en el caso del chorizo. El valor de actividad de agua fue similar en el chorizo $\mathrm{R}$ y $\mathrm{T}$, tanto fresco, como curado; en cambio, el chorizo fresco $\mathrm{R}$ presentó un menor valor de $\mathrm{pH}$ que el chorizo T, si bien el valor de $\mathrm{pH}$ en el producto final fue similar para ambos tratamientos. Por tanto, el cultivo R proporcionó al

Tabla 4. Composición proximal (peso fresco) e índices de secado-maduración del chorizo de Chato Murciano elaborado con diferentes cultivos iniciadores

\begin{tabular}{|c|c|c|c|c|}
\hline \multirow{3}{*}{ Chorizo } & \multicolumn{2}{|c|}{ Fresco } & \multicolumn{2}{|c|}{ Crudo-curado } \\
\hline & $\mathbf{R}$ & $\mathbf{T}$ & $\mathbf{R}$ & $\mathbf{T}$ \\
\hline & $\mathbf{M} \pm \mathbf{D}$ & $\mathbf{M} \pm \mathbf{D}$ & $\mathbf{M} \pm \mathbf{D}$ & $\mathbf{M} \pm \mathbf{D}$ \\
\hline Humedad & $54,4 \pm 0,73$ & $51,5 \pm 1,45$ & $31,9 \pm 1,34$ & $32,5 \pm 3,51$ \\
\hline Proteína total & $17,0 \pm 2,37$ & $16,0 \pm 1,00$ & $25,2 \pm 1,37^{\mathrm{a}}$ & $23,2 \pm 1,19^{b}$ \\
\hline Grasa total & $19,8 \pm 0,74$ & $21,8 \pm 0,81$ & $33,3 \pm 1,08^{b}$ & $34,7 \pm 1,09^{\text {a }}$ \\
\hline $\mathrm{a}_{\mathrm{w}}$ & $0,94 \pm 0,00$ & $0,93 \pm 0,01$ & $0,84 \pm 0,02$ & $0,82 \pm 0,03$ \\
\hline $\mathrm{pH}$ & $6,11 \pm 0,02^{b}$ & $6,33 \pm 0,01^{a}$ & $5,01 \pm 0,40$ & $5,24 \pm 0,26$ \\
\hline Aerobios Mesófilos Totales & $6,59 \pm 0,10^{b}$ & $6,84 \pm 0,09^{a}$ & $8,12 \pm 0,48^{b}$ & $8,77 \pm 0,39^{a}$ \\
\hline Bacterias ácido-lácticas & $6,00 \pm 0,09^{a}$ & $5,62 \pm 0,08^{b}$ & $7,37 \pm 0,14^{b}$ & $8,63 \pm 0,37^{\mathrm{a}}$ \\
\hline Micrococacceae & $6,41 \pm 0,07$ & $6,56 \pm 0,15$ & $5,88 \pm 0,50^{b}$ & $7,37 \pm 0,35^{\mathrm{a}}$ \\
\hline Mohos y Levaduras & $3,31 \pm 0,16$ & $3,10 \pm 0,06$ & $3,97 \pm 0,19$ & $3,74 \pm 0,43$ \\
\hline Acidez de la grasa & $3,27 \pm 0,40$ & $3,16 \pm 1,00$ & $9,12 \pm 0,23$ & $8,85 \pm 1,41$ \\
\hline Índice proteolisis & $11,7 \pm 2,23$ & $12,4 \pm 0,67$ & $12,6 \pm 0,78^{b}$ & $14,2 \pm 0,87^{a}$ \\
\hline $\mathrm{L}^{*}$ & $40,3 \pm 0,41^{\text {a }}$ & $36,3 \pm 1,52^{b}$ & $40,3 \pm 3,42^{a}$ & $34,1 \pm 1,51^{\mathrm{b}}$ \\
\hline$a^{*}$ & $27,9 \pm 0,94^{\mathrm{a}}$ & $23,0 \pm 2,06^{\mathrm{b}}$ & $15,2 \pm 1,76^{\mathrm{a}}$ & $11,9 \pm 2,05^{\mathrm{b}}$ \\
\hline$b^{*}$ & $18,2 \pm 0,70^{\mathrm{a}}$ & $14,5 \pm 1,88^{b}$ & $7,72 \pm 3,03^{a}$ & $4,97 \pm 1,70^{b}$ \\
\hline
\end{tabular}

Tratamientos: Fermentación rápida "R" y tradicional "T".

$\mathrm{M} \pm \mathrm{D}:$ Media \pm Desviación estándar

Medias con diferentes superíndices indican diferencias entre tratamientos en embutido fresco y/o crudo-curado para $\mathrm{P} \leq 0,05$. 
chorizo una mayor velocidad de acidificación que el cultivo $\mathrm{T}$, si bien ambos cultivos alcanzaron un grado final de acidez similar.

Los recuentos medios iniciales de aerobios mesófilos totales, BAL y MIC estuvieron alrededor de $6 \log$ ufc $\mathrm{g}^{-1}$ en ambos tratamientos. El chorizo R partió con mayor carga de BAL que el Chorizo T, por el contrario, los recuentos de MIC, mohos y levaduras fueron similares para ambos tratamientos. Por tanto, la sobredosificación con estafilococos no consiguió aumentar la carga de MIC del chorizo R antes del secado. Tras el secado, aumentaron las poblaciones de casi todos los cultivos estudiados, excepto de MIC en el chorizo R. La carga final de MIC y BAL fue mayor en el chorizo T que en el chorizo R, mientras que los recuentos de mohos y levaduras fueron similares. Con independencia de las dosis de estafilococos y BAL añadidas, una velocidad de acidificación algo más lenta parece favorecer mejor el desarrollo de los cultivos iniciadores durante la maduración del chorizo. Vistos los valores de $\mathrm{pH}$ y $\mathrm{BAL}, P$. pentosaceus parece cumplir su perfil tecnológico como cultivo acidificante rápido, aunque peor adaptado al embutido que L. sakei.

Tabla 5. Puntuaciones de los atributos sensoriales del chorizo Chato Murciano elaborado con diferentes cultivos iniciadores

\begin{tabular}{|l|c|c|}
\hline \multirow{2}{*}{ Chorizo } & \multicolumn{2}{|c|}{ Crudo-curado } \\
\cline { 2 - 3 } & $\mathbf{R}$ & $\mathbf{T}$ \\
\cline { 2 - 3 } & $\mathbf{M} \pm \mathbf{D}$ & $\mathbf{M} \pm \mathbf{D}$ \\
\hline Color magro & $4,15 \pm 0,74$ & $3,90 \pm 0,67$ \\
\hline Color grasa & $2,60 \pm 1,14$ & $2,98 \pm 0,60$ \\
\hline Olor propio & $2,96 \pm 0,58^{\mathrm{b}}$ & $3,29 \pm 0,58^{\mathrm{a}}$ \\
\hline Sabor propio & $3,01 \pm 0,54$ & $3,22 \pm 0,71$ \\
\hline Olor pimentón & $2,97 \pm 0,86$ & $2,79 \pm 0,57$ \\
\hline Sabor pimentón & $3,38 \pm 0,97^{\mathrm{a}}$ & $2,77 \pm 0,72^{\mathrm{b}}$ \\
\hline Olor ácido & $2,27 \pm 0,83^{\mathrm{a}}$ & $1,63 \pm 0,56^{\mathrm{b}}$ \\
\hline Sabor ácido & $2,48 \pm 0,94^{\mathrm{a}}$ & $1,89 \pm 0,87^{\mathrm{b}}$ \\
\hline Olor ajo & $1,75 \pm 0,48^{\mathrm{a}}$ & $1,35 \pm 0,29^{\mathrm{b}}$ \\
\hline Sabor ajo & $1,83 \pm 0,63^{\mathrm{a}}$ & $1,30 \pm 0,33^{\mathrm{b}}$ \\
\hline Olor rancio & $1,09 \pm 0,22^{\mathrm{a}}$ & $1,08 \pm 0,24$ \\
\hline Sabor rancio & $1,13 \pm 0,24$ & $1,13 \pm 0,34^{\mathrm{a}}$ \\
\hline Dureza & $3,77 \pm 0,59^{\mathrm{a}}$ & $2,95 \pm 0,46^{\mathrm{b}}$ \\
\hline Jugosidad & $2,79 \pm 0,69^{\mathrm{b}}$ & $3,21 \pm 0,63^{\mathrm{a}}$ \\
\hline Untuosidad & $2,84 \pm 0,73^{\mathrm{b}}$ & $3,22 \pm 0,60^{\mathrm{a}}$ \\
\hline
\end{tabular}

Tratamientos: Fermentación rápida "R" y tradicional "T".

$\mathrm{M} \pm \mathrm{D}$ : Media \pm Desviación estándar

Medias con diferentes superíndices indican diferencias entre tratamientos en embutido crudo-curado para $\mathrm{P} \leq 0,05$. 
La acidez de la grasa fue similar en el chorizo $\mathrm{T}$ y $\mathrm{R}$, tanto fresco, como crudo-curado, no indicando diferencias en la actividad lipolítica entre ambos cultivos. Tampoco se encontraron diferentes índices de proteolisis entre el chorizo fresco R y T, si bien el chorizo T, el que contaba con mayor carga final de MIC alcanzó un mayor índice de proteolisis tras el secado. Con relación al color, las coordenadas $\mathrm{L}^{*}, \mathrm{a}^{*} \mathrm{y} \mathrm{b}^{*}$ fueron mayores en el tratamiento $\mathrm{R}$ que en el tratamiento T. El chorizo R presentó una mayor $\mathrm{L}^{*}$ y un color con una tonalidad roja algo más intensa que el chorizo $\mathrm{T}$, tanto en fresco, como en producto final. No obstante, el desmenuzado grosero y las diferencias de composición observadas aconsejaban analizar el color del magro y la grasa del chorizo por separado mediante análisis sensorial.

La tabla 5 muestra la evaluación sensorial del Chorizo de Chato Murciano. Se observaron diferencias significativas entre los tratamientos $\mathrm{R}$ y $\mathrm{T}$ para los valores medios de 9 de los 15 atributos sensoriales cuantificados. La nota de color magro y de la grasa fue similar en ambos chorizos, no corroborando las diferencias de reflectancia observadas. La nota de olor propio fue mayor en el chorizo $\mathrm{T}$ que en el chorizo R, aunque la nota de sabor propio fue similar en ambos. La nota media de olor a pimentón fue similar en R y T, sin embargo, el chorizo R presentó un sabor a pimentón algo más intenso que el chorizo T. La acidez del chorizo fue cuantificada como moderada, sin embargo, el panel detectó claramente una mayor acidez (olor y sabor) en el chorizo $\mathrm{R}$ que el chorizo $\mathrm{T}$. El olor y sabor a ajo y rancio fueron muy débiles, aunque se observaron ligeras variaciones entre tratamientos. Por último el chorizo R, el que presentaba una composición algo más magra, presentó a su vez mayor dureza, menor jugosidad y menor untuosidad que el chorizo R. Por tanto, el cultivo tradicional mejoró ligeramente el bouquet del chorizo, y, sobre todo, redujo la acidez del mismo.

\section{Salchichón cular de Chato Murciano}

La tabla 6 muestra la composición proximal y los parámetros de secado-maduración del salchichón de Chato Murciano. Se apreciaron diferencias en la composición proximal que indicarían cierta falta de estandarización de la masa cárnica. El salchichón $\mathrm{T}$ al final de la maduración resultó algo más graso y con un menor grado de deshidratación que el salchichón $\mathrm{R}$, mientras que el porcentaje final de proteínas fue similar para ambos tratamientos. El valor de actividad de agua en fresco fue similar para ambos tratamientos, para después disminuir más en el salchichón T, el que contenía menos agua. El valor de $\mathrm{pH}$ fue claramente más bajo en el salchichón $\mathrm{R}$ que el salchichón $\mathrm{T}$, tanto fresco, como crudo-curado. A diferencia del chorizo, el cultivo $\mathrm{R}$, no sólo proporcionó una mayor velocidad de acidificación al salchichón, sino también un valor final de pH más bajo que el cultivo $\mathrm{T}$.

Los recuentos iniciales de aerobios mesófilos totales, BAL y MIC estuvieron alrededor de $6 \log$ ufc g $^{-1}$ en ambos tratamientos. El salchichón $\mathrm{R}$ presentó una mayor carga inicial de BAL que el salchichón T, alcanzando ambos recuentos finales de BAL similares. Por su parte, la población inicial de MIC fue mayor en el salchichón fresco R que el salchichón T, aunque éste último alcanzó un mayor recuento de MIC tras el secado. Los recuentos de mohos y levaduras fueron similares para ambos tratamientos. Por tanto, el cultivo R, que contenía una dosis de estafilococos tres veces superior, apenas consiguió aumentar ligeramente la carga inicial de MIC del salchichón R. Como en el caso del chorizo, L. sakei proporcionó una acidificación menos intensa que P. pentosaceus, lo que favorecería la proliferación MIC durante la maduración del embutido.

Los valores de acidez de la grasa e índice de proteolisis fueron similares en el salchichón $\mathrm{T}$ y R, tanto fresco, como crudo-curado, no indicando diferencias en la actividad lipolítica $\mathrm{y}$ 
Tabla 6. Composición proximal (peso fresco) e índices de secado-maduración del salchichón de Chato Murciano elaborado con diferentes cultivos iniciadores

\begin{tabular}{|c|c|c|c|c|}
\hline \multirow{3}{*}{ Salchichón } & \multicolumn{2}{|c|}{ Fresco } & \multicolumn{2}{|c|}{ Crudo-curado } \\
\hline & $\mathbf{R}$ & $\mathbf{T}$ & $\mathbf{R}$ & $\mathbf{T}$ \\
\hline & $\mathbf{M} \pm \mathbf{D}$ & $\mathbf{M} \pm \mathbf{D}$ & $\mathbf{M} \pm \mathbf{D}$ & $\mathbf{M} \pm \mathbf{D}$ \\
\hline Humedad & $57,5 \pm 0,14^{\text {a }}$ & $53,9 \pm 2,35^{\mathrm{b}}$ & $31,0 \pm 1,09^{\mathrm{a}}$ & $29,9 \pm 0,77^{\mathrm{b}}$ \\
\hline Proteína total & $15,8 \pm 1,75$ & $16,7 \pm 1,73$ & $26,4 \pm 2,25$ & $24,9 \pm 1,99$ \\
\hline Grasa total & $19,5 \pm 1,41^{\mathrm{b}}$ & $22,3 \pm 1,82^{\text {a }}$ & $33,8 \pm 1,53^{\mathrm{b}}$ & $36,6 \pm 2,31^{a}$ \\
\hline$a_{w}$ & $0,95 \pm 0,00$ & $0,95 \pm 0,00$ & $0,86 \pm 0,02^{\text {a }}$ & $0,81 \pm 0,00^{\mathrm{b}}$ \\
\hline $\mathrm{pH}$ & $6,05 \pm 0,02^{b}$ & $6,23 \pm 0,01^{a}$ & $4,58 \pm 0,17^{b}$ & $5,15 \pm 0,23^{a}$ \\
\hline Aerobios Mesófilos Totales & $6,63 \pm 0,07^{\mathrm{b}}$ & $6,97 \pm 0,00^{a}$ & $8,76 \pm 0,06$ & $8,86 \pm 0,19$ \\
\hline Bacterias ácido-lácticas & $6,12 \pm 0,06^{\text {a }}$ & $5,92 \pm 0,02^{\mathrm{b}}$ & $8,70 \pm 0,04$ & $8,76 \pm 0,23$ \\
\hline Micrococacceae & $6,48 \pm 0,05^{\text {a }}$ & $6,37 \pm 0,00^{\mathrm{b}}$ & $5,98 \pm 0,11^{\mathrm{b}}$ & $6,97 \pm 0,17^{\mathrm{a}}$ \\
\hline Mohos y Levaduras & $3,86 \pm 0,12$ & $3,50 \pm 0,21$ & $3,95 \pm 0,17$ & $3,93 \pm 0,31$ \\
\hline Acidez de la grasa & $2,04 \pm 0,51$ & $2,60 \pm 0,78$ & $7,46 \pm 0,32$ & $7,75 \pm 1,59$ \\
\hline Índice proteolisis & $10,6 \pm 1,41$ & $9,52 \pm 1,22$ & $11,9 \pm 2,40$ & $12,3 \pm 1,14$ \\
\hline $\mathrm{L}^{*}$ & $47,5 \pm 0,66$ & $45,3 \pm 3,04$ & $46,8 \pm 2,32$ & $46,2 \pm 1,35$ \\
\hline$a^{*}$ & $18,6 \pm 0,30^{\text {a }}$ & $11,6 \pm 1,20^{b}$ & $13,6 \pm 1,11^{\text {a }}$ & $10,2 \pm 0,89^{b}$ \\
\hline$b^{*}$ & $4,14 \pm 0,39$ & $5,50 \pm 1,14$ & $3,82 \pm 1,32{ }^{a}$ & $1,75 \pm 0,49^{b}$ \\
\hline
\end{tabular}

Tratamientos: Fermentación rápida "R" y tradicional "T".

$\mathrm{M} \pm \mathrm{D}$ : Media \pm Desviación estándar

Medias con diferentes superíndices indican diferencias entre tratamientos en embutido fresco y/o crudo-curado para $\mathrm{P} \leq 0,05$.

proteolítica entre ambos cultivos. Los valores de $\mathrm{L}^{*}$ fueron también similares para ambos tratamientos; sin embargo, el salchichón crudocurado R presentó un mayor valor de $\mathrm{a}^{*} \mathrm{y} \mathrm{b}^{*}$, es decir, un color con una tonalidad rojo-azulada más intensa que el salchichón T. Teniendo en cuenta las diferencias de composición detectadas, y que, al igual que el chorizo, el salchichón es un embutido de picado grosero, estas diferencias de reflectancia debían ser corroboradas mediante análisis sensorial diferenciado del color del magro y de la grasa.

La tabla 7 muestra la evaluación sensorial del Salchichón cular de Chato Murciano. Sólo se observaron diferencias significativas entre los tratamientos $\mathrm{R}$ y $\mathrm{T}$ para los valores medios de algunos atributos sensoriales menores. El color magro y la grasa obtuvieron puntuaciones similares, no corroborando las diferencias de reflectancia observadas entre tratamientos. La nota de olor y sabor propios fueron también similares para ambos tratamientos, el olor a pimenta fue algo más intenso en el salchichón $\mathrm{R}$ que en el salchichón $\mathrm{T}$, mientras que el sabor a pimenta fue similar. Como en el caso del chorizo, el panel detectó claramente una mayor acidez en el salchichón $\mathrm{R}$ que en el salchichón $\mathrm{T}$, mientras que el olor y sabor a ajo o rancio fueron imperceptibles. Por último, el salchichón $\mathrm{R}$, el que presentaba un mayor contenido en humedad y un menor contenido en grasa, presentó a su vez una menor jugosidad y una menor un- 
Tabla 7. Puntuaciones de los atributos sensoriales del salchichón Chato Murciano elaborado con diferentes cultivos iniciadores

\begin{tabular}{|l|c|c|}
\hline \multirow{2}{*}{ Chorizo } & \multicolumn{2}{|c|}{ Crudo-curado } \\
\cline { 2 - 3 } & $\mathbf{R}$ & $\mathbf{T}$ \\
\cline { 2 - 3 } & $\mathbf{M} \pm \mathbf{D}$ & $\mathbf{M} \pm \mathbf{D}$ \\
\hline Color magro & $3,86 \pm 0,40$ & $3,88 \pm 0,51$ \\
\hline Color grasa & $3,05 \pm 0,57$ & $3,28 \pm 0,79$ \\
\hline Olor propio & $3,37 \pm 0,53$ & $3,53 \pm 0,60$ \\
\hline Sabor propio & $3,51 \pm 0,49$ & $3,60 \pm 0,73$ \\
\hline Olor pimienta & $2,37 \pm 0,68^{\mathrm{a}}$ & $2,03 \pm 0,71^{\mathrm{b}}$ \\
\hline Sabor pimienta & $2,45 \pm 0,86$ & $2,41 \pm 0,76$ \\
\hline Olor acido & $1,70 \pm 0,65$ & $1,59 \pm 0,61$ \\
\hline Sabor acido & $2,23 \pm 0,65^{\mathrm{a}}$ & $1,69 \pm 0,56^{\mathrm{b}}$ \\
\hline Olor rancio & $1,00 \pm 0,00^{\mathrm{b}}$ & $1,21 \pm 0,38^{\mathrm{a}}$ \\
\hline Sabor rancio & $1,00 \pm 0,00^{\mathrm{b}}$ & $1,16 \pm 0,31^{\mathrm{a}}$ \\
\hline Dureza & $3,44 \pm 0,45^{\circ}$ & $3,44 \pm 0,46$ \\
\hline Jugosidad & $2,70 \pm 0,48^{\mathrm{b}}$ & $3,22 \pm 0,49^{\mathrm{a}}$ \\
\hline Untuosidad & $2,77 \pm 0,42^{\mathrm{b}}$ & $3,34 \pm 0,63^{\mathrm{a}}$ \\
\hline
\end{tabular}

Tratamientos: Fermentación rápida "R" y tradicional "T".

$\mathrm{M} \pm \mathrm{D}$ : Media \pm Desviación estándar

Medias con diferentes superíndices indican diferencias entre tratamientos en embutido crudo-curado para $\mathrm{P} \leq 0,05$.

tuosidad que el salchichón T, si bien la dureza fue similar en ambos. En suma, el cultivo tradicional redujo la acidez del salchichón aunque no mejoró el enrojecimiento ni el bouquet.

\section{DISCUSIÓN}

La composición de los embutidos crudocurados varía considerablemente dependiendo de sus ingredientes y grado de deshidratación. De acuerdo con la norma de calidad para embutidos crudo-curados, tanto el chorizo, como el salchichón de Chato Murciano, estarían incluidos en la categoría extra, la de mayor calidad composicional (Orden 7-2-1980). En cualquier caso, pese a los avances tecnológicos actuales, no siempre es posible conseguir una completa estandarización de la composición de la masas cárnicas, más cuando se procesan a pequeña escala materias primas cárnicas procedentes de cerdos rústicos cuyas características de la canal y de la carne son menos reproducibles que en los cerdos comerciales. Las diferencias en el contenido en humedad o grasa de los embutidos pueden afectar a su valor de actividad de agua $\mathrm{y}$, a igualdad de otros factores, al crecimiento de las bacterias fermentativas (Hugas y Monfort, 1997; Ammor y Mayo, 2007). Sin embargo, la menor actividad de agua del salchichón elaborado con cultivo tradicional no estuvo asociada a un menor crecimiento de BAL y MIC.

Numerosos estudios recomiendan el uso de cultivos iniciadores de BAL y MIC en chorizo y salchichón para minimizar ciertos riesgos tec- 
nológicos, como una acidificación inadecuada o la proliferación de microorganismos patógenos y alterantes (Sanz et al., 1997; González et al., 1999; Ammor y Mayo, 2007; Cenci-Goga et al., 2008; González y Díez, 2002; Bedia et al., 2011; Casquete et al., 2011). En estos estudios las mezclas de BAL y MIC proporcionaron mejores resultados que la fermentación natural o la adición de ambos cultivos por separado, incluyendo mejoras del color, bouquet y/o textura del chorizo y/o salchichón, aunque no comparan cultivos iniciadores con sobredosificación estafilococos como en el presente estudio.

Los cultivos comerciales testados proporcionaron características de maduración similares al chorizo y el salchichón de Chato Murciano, pese a su diferente formulación y picado. Con independencia del cultivo utilizado, las concentraciones de BAL y MIC de la masa fresca estuvieron bastante por debajo de las dosis adicionadas, hecho usual en los estudios de fermentación anteriormente citados. Aunque los cultivos iniciadores son revivificados, disueltos en agua libre de cloro y mezclados convenientemente, no es posible asegurar una total supervivencia de los mismos en grandes masas de producto. En cualquier caso, ambos cultivos permitieron alcanzar con posterioridad concentraciones funcionales de BAL y MIC (Carrascosa, 2001). Por su parte el crecimiento de mohos y levaduras, el grupo fermentativo minoritario, dependería más de la contaminación ambiental y las condiciones de humedad y temperatura en la superficie del embutido durante el secado. Se han descrito recuentos finales de 8-9 log ufc $\mathrm{g}^{-1}$ de BAL, 4-7 log ufc $\mathrm{g}^{-1}$ de MIC y 2-6 log ufc $\mathrm{g}^{-1}$ de mohos y levaduras en diversos tipos de chorizo (Dolazo et al., 1998, Cápita et al., 2006; González et al., 1999; González y Díez, 2002) y salchichón-salami (Sanz et al., 1997; Pérez et al., 1999; González et al., 1999; Lizaso et al., 1999; Cápita et al., 2006; Casaburi et al., 2007; Cenci-Goga et al., 2008; Aro et al., 2010; Bañón et al., 2010; Bedia et al., 2011; Casquete et al., 2011).
$P$. pentosaceus presentó una velocidad acidificante superior $a$ L. sakei, disminuyendo con más eficacia el $\mathrm{pH}$ del embutido, lo que explicaría las diferencias de acidez observadas. Por su parte, la combinación de L. sakei, S. xylosus y $S$. carnosus permitió alcanzar mayores recuentos finales de bacterias fermentativas, consiguiendo además moderar la caída del pH, mejorar ligeramente el bouquet, en particular del chorizo, y sobre todo, reducir la acidez de ambos embutidos. L. sakei es una bacteria autóctona de la carne bien adaptada a este tipo de embutidos, que proporciona una velocidad de acidificación más lenta que $P$. pentosaceus (Hugas y Monfort, 1997; Leroy et al., 2006; Ammor y Mayo, 2007). Las condiciones de actividad de agua, $\mathrm{pH}$, presencia de nutrientes y disponibilidad de oxígeno existentes al inicio de la fermentación, favorecen el rápido desarrollo de los microorganismos de la carne y añadidos, en especial aerobios y MIC, antes que la progresiva deshidratación, acidificación y falta de oxígeno provocada por la fermentación láctica, junto con la actuación de los nitritos, reduzcan sus recuentos considerablemente, en favor de las BAL, que son más resistentes en estas condiciones (Lücke, 2000). González y Díez (2002) comprobaron que la adición de un cultivo de L. sakei inhibía el crecimiento de Enterobateriacceae en el chorizo pero no de Micrococacceae, si bien Sanz et al., (1997) encontraron inhibición de MIC al adicionar BAL al salchichón.

Cuando se emplea un cultivo acidificante rápido, como, $P$. pentosaceus, la sobredosificación con $S$. Xilosus no parece aportar beneficios tecnológicos adicionales al salchichón o al chorizo, ya que apenas se consiguió aumentar la carga inicial de MIC con respecto al fermento tradicional. Los recuentos microbiológicos en masa fresca sugieren que la dosis inicial de estafilococos sería menos relevante que la propia adaptación de éstos al medio. No obstante, la baja temperatura de secado y la falta de una etapa específica de fermentación podrían quizás 
haber contribuido a restar eficacia a los cultivos de estafilococos, pese a que el secado duró 8 semanas y a que los valores de actividad de agua y $\mathrm{pH}$ fueron moderados para este tipo de embutidos. En cualquier caso, el uso de cultivos adicionales de MIC consigue pobres resultados y aumenta los costes de producción, no siendo aconsejable en estos embutidos.

A excepción del $\mathrm{pH}$, las diferencias entre cultivos en los parámetros de maduración fueron en general poco relevantes. El valor final de actividad de agua depende del grado de desecación, aunque en estos embutidos suele estar en valores de 0,89-0,90, mientras que el $\mathrm{pH}$ final suele estar en torno a 4,6-5,1, siendo ligeramente superior en el chorizo que en el salchichón (Dolazo et al., 1998; Lizaso et al., 1999; Pérez et al., 1999; Gimeno et al., 2001; González y Díez, 2002; Cápita et al., 2006; González et al., 1999; Casaburi et al., 2007; Cenci-Goga et al., 2008; Aro et al., 2010; Bañón et al., 2010; Bedia et al., 2011; Casquete et al., 2011). Los formulados comerciales utilizados en ambos embutidos de Chato Murciano contenían un $0,3 \%$ de glucosa y la máxima dosis de nitritos y nitratos permitida por la Legislación, lo que a priori garantizaba una correcta fermentación de los mismos (González et al., 1999). El descenso del $\mathrm{pH}$ es más rápido durante los primeros días de maduración, debido a la fermentación de los azúcares de la mezcla cárnica por las BAL, con la consiguiente producción de ácido láctico. Conforme avanza el secado, el crecimiento de BAL se ralentiza al agotarse los azúcares y al bajar la actividad de agua, e incluso el pH puede aumentar ligeramente por reacción del ácido láctico con grupos amino procedentes de la degradación peptídica que llevan a cabo proteasas endógenas y bacterianas (Hugas y Monfort, 1997).

Los estafilococos con actividad nitrato-reductasa contribuyen a la formación del color en los embutidos fermentados tipo salchichón (Gøtterup et al., 2008). Cabría haber esperado una mayor contribución del cultivo $\mathrm{R}$ al enro- jecimiento del salchichón, ya éste no contiene especias colorantes, como el pimentón del chorizo. Similares recuentos de MIC en la masa fresca explicarían que no se hayan producido diferencias relevantes en el color. La no correspondencia entre la evaluación objetiva y subjetiva del color se debería a que los granos de grasa y de carne reflejan la luz de forma muy diferente, de ahí que algunas diferencias de color CIELAB se deben a menudo, más a la propia heterogeneidad de la loncha, que a diferencias reales de color, en especial en embutidos poco desmenuzados. Se han descrito coordenadas de color de 39-54 (L*), 8-26 (a*) y 11-18 (b*) en chorizo (Gimeno et al., 2001) y de 47-53 (L*), 9-16 (a*) y 4-9 (b*) en salchichón (Pérez et al., 1999, Rubio et al., 2008; Bedia et al., 2010). Por su parte, la acidez de la grasa y el grado de proteolisis estuvo en valores bastante parecidos a los publicados en salchichón por Sanz et al., (1997) y Lizaso et al., (1999). La adición de S. xilosus incrementó los valores $\mathrm{L}^{*} \mathrm{a} * \mathrm{~b} *$ y del Salami, pero no afectó a su contenido en ácidos grasos libres (Fiorentini et al., 2010). Por el contrario, otros estudios han dejado claro la capacidad proteolítica y lipolítica de S. xilosus en este tipo de embutidos fermentados (Aro et al., 2010; Martín et al., 2007, Casquete et al., 2011; Casaburi et al., 2007). Las bacterias fermentativas juegan un importante papel en la formación de compuestos volátiles y no volátiles implicados en el aroma y sabor de estos embutidos, como los ácidos láctico y acético, y diferentes alquenos, alcoholes, cetonas, aldehídos y aminoácidos libres, entre otros (Montel et al., 1998; Mateo et al., 1996).

\section{BIBLIOGRAFÍA}

ACHAMUR. 2011. Asociación de Criadores de Cerdo Chato Murciano. Comunicación interna.

AMMOR M. S., MAYO B. 2007. Selection criteria for lactic acid bacteria to be used as functional starter cultures in dry sausage 
production: An update. Meat Sci. 76: 138146.

ARO J.M., NYAM-OSOR P., TSUJI K., SHIMADA K., FUKUSHIMA M., SEKIKAWA M. 2010. The effect of starter cultures on proteolytic changes and amino acid content in fermented sausages. Food Chem. 119: 279-285.

BAÑóN S., MÉNDEZ L., ALMELA E., SERRANO R., BEDIA M. 2009. Evaluation of the fat content in a small-calibre Salami made with pork from Chato Murciano breed. En: Options Méditerranéennes. Ed. Instituto Agronómico Mediterráneo de Zaragoza, España (en prensa).

BAÑóN S., BEDIA M., ALMELA E., MARTÍNEZ P.J. 2010. Improving the quality of dry-cured sausage using pork from rustic breed. Anim. Food Sci. 19: 240.

BEDIA M., MÉNDEZ, L., SERRANO R., AZNAR A.G., BAÑóN, S. 2010. Development of Chato Murciano Sobrasada prepared using "Appellation of Murcia Origin" Paprika. En: Options Méditerranéennes. Ed. Instituto Agronómico Mediterráneo de Zaragoza, España (en prensa).

BEDIA M., MÉNDEZ L., BAÑÓN, S. 2011. Evaluation of different starter cultures (Staphylococci plus Lactic Acid Bacteria) in semi-ripened Salami stuffed in swine gut. Meat Sci. 87: 381-386.

BENITO M.J., MARTIN A., ARANDA E., PÉREZ-NEVADO F., RUIZ-MOYANO S., CÓRDOBA M.G. 2007. Characterization and selection of autochthonous lactic acid bacteria isolated from traditional Iberian dry-fermented salchichón and chorizo sausages. J. Food Sci. 72:193-201.

CALVO J.H., LOBERA J., OSTA R., ZARAGOZA P. 2000. Caracterización genética de la raza porcina Chato Murciano. Arch. Zootech. 49: 53-58.

CÁPITA R., LLORENTE S., PRIETO M., ALONSO C. 2006. Microbiological Profiles, $\mathrm{pH}$, and Titratable Acidity of Chorizo and Salchichón (Two Spanish Dry Fermented Sausages) Manufactured with Ostrich, Deer, or Pork Meat. J. Food Prot. 69: 11831189.

CARRASCOSA S. 2001. Cultivos iniciadores para la industria de la carne. En: Enciclopedia de la carne y los productos cárnicos. Ed. Martin, Madrid, España. 943-966 pp.

CASABURI A., ARISTOY M.C., CAVELLA V., DI MONACO R., ERCOLINI D., TOLDRÁ F., VILLANI, F. 2007. Biochemical and sensory characteristics of traditional fermented sausages of Vallo di Diano (Southern Italy) as affected by the use of starter cultures. Meat Sci. 76: 295-307.

CASQUETE R., BENITO M.J., MARTÍN A., RUIZ-MOYANO S., HERNÁNDEZ A., CÓRDOBA M.G. 2011. Effect of autochthonous starter cultures in the production of "salchichón", a traditional Iberian dryfermented sausage, with different ripening processes. Food Sci. Tech 44: 1562-1571.

CENCI-GOGA B.T., RANUCCI D., MIRAGLIA D., CIOFFI A. 2008. Use of starter cultures of dairy origin in the production of salame nostrano, an Italian dry-cured sausage. Meat Sci. 78: 381-390.

DOLAZO F., STEINHOF U., RING C., PFEIFFER S. 1998. Microbiological status of the Spanish fermented sausage "Chorizo Gallego" - Sensory, chemical and chemo-physical properties. Fleischwirtschaft 78: 1089-1092. FIORENTINI Â.M., CORTEZ M., BERTOL T.M., CUNHA J A., SEBASTIÃO, E. 2010. Influence of a native strain of Staphylococcus xylosus on the microbiological, physicochemical and sensorial characteristics on Milano salami type. BABT 53 (4): 961-974.

GALIÁN M., POTO A., SANTAELLA M., PEINADO B. 2008. Effects of the rearing system on the quality traits of the carcass, meat and fat of the Chato Murciano pig. Anim. Sci. J. 79 (4): 487-497.

GALIÁN M., POTO A., PEINADO B. 2009. Carcass and meat quality traits of the Cha- 
to Murciano pig slaughtered at different weights. Livest. Sci. 124: 314-320.

GIMENO O., ASTIASARÁN I., BELLO J. 2001. Calcium ascorbate as a potential partial substitute for $\mathrm{NaCl}$ in dry fermented sausages: effect on colour, texture and hygienic quality at different concentrations. Meat Sci. 57: 23-29.

GONZÁLEZ B., DÍEZ V. 2002. The effect of nitrite and starter culture on microbiological quality of "chorizo" - a Spanish dry cured sausage. Meat Sci. 60 (3): 295-298.

GONZÁLEZ M.E., SIERRA M., GARCIA M.L., GARCIA M.C., OTERO A. 1999. The influence of manufacturing and drying conditions on the survival and toxinogenesis of Staphylococcus aureus in two Spanish dry sausages (chorizo and salchichon). Meat Sci. 52(4): 411-419.

GØTTERUP J., OLSEN K., KNØCHEL S., TJENER K., STAHNKE L.H., MØLLER, J.K.S. 2008. Colour formation in fermented sausages by meat-associated staphylococci with different nitrite- and nitrate-reductase activities. Meat Sci. 78: 492-501.

HUGAS M., MONFORT J. 1997. Bacterial starter cultures for meat fermentation. Food Chem. 59: 547-554.

ISO 1443. 1973. International Organization for Standardization Publications. Meat and meat products - Determination of total fat content. <http://www.iso.org >.

ISO 937. 1978. International Organization for Standardization Publications. Meat and meat products. Determination of nitrogen content. www.iso.org.

ISO 8586-1. 1993. International Organization for Standardization Publications. Sensory analysis Methodology. General guidance for the selection and training and monitoring of assessors. Part 1. Selected assessors. www.iso.org.

ISO 1442. 1997. International Organization for Standardization Publications. Meat and meat products - Determination of moisture content. <http://www.iso.org >.
ISO 936. 1998. International Organization for Standardization Publications. Meat and meat products. Determination of ash. www.iso.org. ISO 15214. 1998. International Organization for Standardization Publications. Microbiology of food and animal feeding stuffs. Horizontal method for the enumeration of mesophilic lactic acid bacteria. Colony-count technique at 30 degrees C. www.iso.org.

ISO 2917. 1999. International Organization for Standardization Publications. Meat and meat products. Measurement of $\mathrm{pH}$. Reference method. www.iso.org.

ISO 4121. 2003. International Organization for Standardization Publications. Sensory Analysis Methodology. Evaluation of food products by methods using scales. www.iso.org.

ISO 4833. 2003. International Organization for Standardization Publications. Microbiology of food and animal feeding stuffs. Horizontal method for the enumeration of microorganisms. Colony-count technique at $30 \mathrm{de}-$ grees C. www.iso.org.

ISO 21807. 2004. International Organization for Standardization Publications. Microbiology of food and animal feeding stuffs. Determination of water activity. www.iso.org.

ISO 21527-2. 2008 International Organization for Standardization Publications. Microbiology of food and animal feeding stuffs. Horizontal method for the enumeration of yeasts and moulds - Part 2: Colony count technique in products with water activity greater than 0.95. www.iso.org.

LEROY F., VERLUYTEN J., DE VUYST L. 2006. Functional meat starter cultures for improved sausage fermentation. Int. J. Food Microbiol. 106: 270-285.

LIZASO G., CHASCO J., BERIAIN M.J. 1999. Microbiological and biochemical changes during ripening of salchichón, a Spanish dry cured sausage. Food Microbiol. 16: 219-228.

LÜCKE F.K. 2000. Utilization of microbes to process and preserve meat. Meat Sci. 56: 105-115. 
MARTÍN A., COLÍN B., ARANDA E., BENITO M. J., CÓRDOBA M.G. 2007. Characterization of Micrococcaceae isolated from Iberian dry-cured sausages. Meat Sci. 75: 696-708.

MARTÍNEZ P.J., GARRIDO M.D., BANÓN S. 2008. Stabilization by chilling of Sobrasada from Chato Murciano pigmeat manufactured without preservatives. Ann. Vet. Mu. 24: 73-80.

MARTÍNEZ-CACHÁ A., SALAZAR E., TEJADA L., ABELLÁN A., GIRÓN F., NAVAS J., CARAVACA G., CAYUELA J.M. 2009. Preferencia y grado de aceptación en consumidores de embutidos de cerdo chato murciano y de cerdo blanco. En "Libro de resúmenes del V Congreso Nacional de Ciencia y Tecnología de Alimentos, Murcia, España”. 314 pp.

MATEO J., DOMÍNGUEZ M.C., AGUIRREZABAL M.M., ZUMALACARREGUI J.M. 1996. Taste compounds in chorizo and their changes during ripening. Meat Sci. 44(4): 245-254.

MONTEL M.C., MASSON F., TALON R. 1998. Bacterial role in flavour development. Meat Sci. 49: 111-123.

ORDEN 7-2-1980. Norma de calidad para productos cárnicos embutidos crudos-curados en el mercado interior. $\mathrm{BOE} 21 / 3 / 1980$ 70: 6280-6284.

PEINADO B., POTO A., GIL F., LÓPEZ

G. 2004. Characteristics of the carcass and meat of the Chato Murciano pig. Livest. Prod. Sci 90: 285-292.

PEINADO B., POTO A., VEGA-PLA J. L., MARTÍNEZ A., BARBA C., DELGADO, J. V. 2003. Genetic study of the Chato Murciano pig breed under a recovery program. Arch. Zootec. 52: 273-278.

PÉREZ J.A., SAYAS M.E., FERNÁNDEZ J., ARANDA V. 1999. Physico- chemical characteristics of Spanishtype dry-cured sausage. Food Res. Int. 32: 599-607.

POTO A., GALIÁN B., PEINADO B. 2007. Chato Murciano pig and its crosses with Iberian and Large White pigs, reared outdoors. Comparative study of the carcass and meat characteristics. Livest. Sci. 111: 96.

REAL DECRETO 997/1999, de 11 de junio, sobre fomento de las razas autóctonas españolas de protección especial en peligro de extinción. BOE 12/06/1999: 22598-22599.

REAL DECRETO 2129/2008, de 26 de diciembre, por el que se establece el Programa nacional de conservación, mejora y fomento de las razas ganaderas. BOE 27/1/2009: 9211-9236.

RUBIO B., MARTÍNEZ B., SÁNCHEZ M.J., GARCÍA-CACHÁN M.D., ROVIRA, J., JAIME I. 2008. Effect of the packaging method and the storage time on lipid oxidation and colour stability on dry fermented sausage Salchichón manufactured with raw material with a high level of mono and polyunsaturated fatty acids. Meat Sci. 80, 1182-1187.

SALAZAR E., TEJADA L., MARTÍNEZ-CACHÁ A., POTO A., ABELLÁN A., GIRÓN F., PEINADO B., CAYUELA J.M. 2009. Estudio comparativo de las características sensoriales de lomo curado de cerdo blanco y Chato Murciano. En: "Libro de resúmenes del $\mathrm{V}$ Congreso Nacional de Ciencia y Tecnología de Alimentos, Murcia, España”. 246 pp. SANZ Y., FLORES J., TOLDRÁ, F., FERIA, A. 1997. Effect of pre-ripening on microbial and chemical changes in dry fermented sausages. Food Microbiol. 14, 575-582. 